http://jmscr.igmpublication.org/home/ ISSN (e)-2347-176x ISSN (p) 2455-0450

crossref DOI: https://dx.doi.org/10.18535/jmscr/v8i3.105

\title{
Assessment and Outcome of Thyroid Function during First Trimester Pregnancy in Tertiary Hospital
}

Authors

\author{
Shrutika Gobbur ${ }^{1}$, Rameshwari Nisty ${ }^{2}$, Gangambika Nisty ${ }^{3}$
}

Dept of Obstetrics and Gynaecology Esic Medical College, Kalaburgi

\section{Introduction}

Thyroid disorders are among the common endocrine problems in pregnant women. Pregnancy is a physiological state, associated with significant, but reversible changes in thyroid function. Thyroid hormone status shows variation during normal pregnancy, so evaluating the thyroid function at early pregnancy may avoid untoward adverse outcomes.

\section{Methodology}

\section{Aims and Objectives}

1. Estimating proportion of thyroid dysfunction in first trimester pregnant women attending tertiary hospital.

2. Estimating TPO antibodies in women with abnormalities of thyroid profile.

All the patients attending to OBG OPD in first trimester for antenatal check up. Women confirmed to be in the first trimester of pregnancy by LMP will be selected for the study. It will be assessed whether they fit in to the inclusion criteria.

1) A thorough general physical examination with reference to Pulse, blood pressure, temperature, respiratory rate will be noted followed by Cardiovascularsystem, Central nervous system, Respiratory system, local thyroid examination and abdominal examination will be done.

2) Women are sent for thyroid hormone profile testing FT3, FT4 \& TSH by ELISA reader method.

3) The normal range of TSH in first trimester is $0.1-2.5 \mu \mathrm{u} / \mathrm{dl}$ values outside this range will be considered abnormal. All such women will be asked to undergo Thyroid Peroxidase antibody testing.

Inclusion criteria for the study group

1) $<13$ weeks gestation

2) Singleton pregnancy

3) Age group of 18 to 45 years.

Exclusion criteria for the study group:

1) Known chronic disorders diabetes mellitus and hypertension

2) Pregnant women with known thyroid abnormalities and on treatment.

3) Pregnant women not willing to give consent

\section{Results}

Study Design: A hospital based prospective study conducted on135 first trimester pregnant women, to evaluate the thyroid status in them;and also to determine any thyroid abnormalities associated with it. 
A $2 \mathrm{ml}$ of venous blood sample was collected from the antecubital vein in all the subjects and the thyroid profile (FT3, FT4 and TSH) was then determined by using chemiluminesence immune assay method. The data was then tabulated and statistically analysed.

Statistical tests used are:

Mean: measure of central tendency

Median: measure of dispersion

Independent ' $t$ ' test : was used to compare quantitative variable like FT3, FT4, and TSH between any two groups or characteristics or variables

ANOVA test: was used to compare quantitative variable like FT3, FT4, and TSH between any more than two groups or characteristics or variables.

Study observed that, maximum number of cases $76(56.3 \%)$ were belongs to in the age group of 21 25 years and minimum no. of cases were $8(5.9 \%)$ belong to the age group of $\geq 31$. The mean and SD of age was $24.5 \pm 3.57$ (Table 1)

Table No.1: Age wise distribution of cases

\begin{tabular}{|l|c|c|}
\hline Age in years & No. of cases & Percentage \\
\hline$\leq \mathbf{2 0}$ & 17 & 12.6 \\
\hline $\mathbf{2 1 - 2 5}$ & 76 & 56.3 \\
\hline $\mathbf{2 6 - 3 0}$ & 34 & 25.2 \\
\hline$\geq \mathbf{3 1}$ & 8 & 5.9 \\
\hline Total & $\mathbf{1 3 5}$ & $\mathbf{1 0 0 . 0}$ \\
\hline Mean \pm SD & \multicolumn{2}{|c|}{$\mathbf{2 1 . 1 9} \pm \mathbf{1 . 9 3}$} \\
\hline
\end{tabular}

$\mathrm{NS}=$ not significant, $\mathrm{S}=$ significant, $\mathrm{HS}=$ highly significant, VHS=very highly significant

Study observed that, maximum number of cases $81(60.0 \%)$ were multigravida cases. Out of which maximum number of cases were belongs to G2, followed by G3, G4 and G5 cases were $51(37.8 \%), 21(15.5 \%), 7(5.2 \%)$ and $2(1.5 \%)$ respectively. There were $54(40.0 \%)$ of primi cases (Table 2)

Table No.2: Obstetrics parity wise distribution of cases

\begin{tabular}{|c|c|c|c|}
\hline \multicolumn{2}{|c|}{ Obstetrics parity } & No. of cases & Percentage \\
\hline \multicolumn{2}{|l|}{ Primi } & 54 & 40.0 \\
\hline \multirow{4}{*}{ Multigravida } & G2 & 51 & 37.8 \\
\hline & G3 & 21 & 15.5 \\
\hline & G4 & 7 & 5.2 \\
\hline & G5 & 2 & 1.5 \\
\hline \multicolumn{2}{|l|}{ Total } & 135 & 100.0 \\
\hline
\end{tabular}

Study observed that, maximum number of cases $68(50.4 \%)$ were belongs to in the gestational age group of 9 to11 weeks and minimum no. of cases were $12(8.9 \%)$ belong to the gestational age group of $\geq 12$ weeks. The mean and SD of gestational age was $10.20 \pm 1.43$ (Table 3).

Table No.3: Period of Gestation wise distribution of cases

\begin{tabular}{|l|c|c|}
\hline $\begin{array}{l}\text { POG } \\
\text { In weeks }\end{array}$ & No. of cases & Percentage \\
\hline$\leq \mathbf{8}$ weeks & 15 & 11.1 \\
\hline 8--9 weeks & 17 & 12.6 \\
\hline 9--10 weeks & 31 & 23.0 \\
\hline $\mathbf{1 0 - 1 1}$ weeks & 37 & 27.4 \\
\hline $\mathbf{1 1 - 1 2}$ weeks & 23 & 17.0 \\
\hline$\geq \mathbf{1 2}$ weeks & 12 & 8.9 \\
\hline Total & $\mathbf{1 3 5}$ & $\mathbf{1 0 0 . 0}$ \\
\hline Mean \pm SD & \multicolumn{2}{|c|}{$\mathbf{1 0 . 2 0} \pm \mathbf{1 . 4 3}$} \\
\hline
\end{tabular}

Study observed that, there were $21(15.5 \%)$ of thyroid dysfunction cases in the study. The proportion of thyroid dysfunction with normal cases were 5.4:1 and the hospital incidence rate of thyroid dysfunction in first trimester pregnant women was $15.5 \%$ (Table 4).

Study reveals that, there was no statistical significance difference of normal and thyroid dysfunction cases in relation with age $(\mathrm{P}>0.05)$.

Table No.4: Age wise comparison of normal and thyroid dysfunction cases

\begin{tabular}{|c|c|c|c|c|c|c|}
\hline \multirow[t]{2}{*}{ Age in years } & \multicolumn{2}{|c|}{ Normal } & \multicolumn{2}{|c|}{$\begin{array}{c}\text { Thyroid } \\
\text { dysfunction }\end{array}$} & \multicolumn{2}{|c|}{ Total } \\
\hline & No. & $\%$ & No. & Ratio \% & No. & $\%$ \\
\hline$\leq \mathbf{2 0}$ & 16 & 94.1 & 1 & 5.9 & 17 & 12.6 \\
\hline $21-25$ & 62 & 81.6 & 14 & 18.4 & 76 & 56.3 \\
\hline 26-30 & 29 & 85.3 & 5 & 14.7 & 34 & 25.2 \\
\hline$\geq 31$ & 7 & 87.5 & 1 & 12.3 & 8 & 5.9 \\
\hline Total & 114 & 84.4 & 21 & 15.6 & 135 & 100.0 \\
\hline $\begin{array}{l}\text { Chi-square test value } \\
\text { P-value \& Significance }\end{array}$ & $\chi_{\text {yates }}^{2}$ & 973 & $P>0.0$ & NS & & \\
\hline
\end{tabular}

$\mathrm{NS}=$ not significant, $\mathrm{S}=$ significant, $\mathrm{HS}=$ highly significant, VHS=very highly significant 
Study reveals that, there was statistically very highly significance association normal and thyroid dysfunction cases in relation with period of gestation $(\mathrm{P}<0.001)$.
Higher the period of gestation age have significantly more number of thyroid dysfunction cases as compare to lower gestation age in relation with normal cases (Table 5)

Table No.5: Comparison of Period of Gestation with normal and thyroid dysfunction

\begin{tabular}{|l|c|c|c|c|c|c|}
\hline \multirow{2}{*}{$\begin{array}{l}\text { POG weeks } \\
\text { In }\end{array}$} & \multicolumn{2}{|c|}{ Normal } & Thyroid dysfunction & \multicolumn{2}{c|}{ Total } \\
\cline { 2 - 8 }$\leq \mathbf{8}$ weeks & 15 & 100.0 & 0 & 0.0 & 15 & 15.0 \\
\hline $\mathbf{8 - - 9}$ weeks & 16 & 94.1 & 1 & 5.9 & 17 & 17.0 \\
\hline 9--10 weeks & 29 & 93.5 & 2 & 6.5 & 31 & 31.0 \\
\hline $\mathbf{1 0 - 1 1}$ weeks & 30 & 81.0 & 7 & 19.0 & 37 & 37.0 \\
\hline $\mathbf{1 1 - 1 2}$ weeks & 15 & 65.2 & 8 & 34.8 & 23 & 23.0 \\
\hline$\geq \mathbf{1 2}$ weeks & 9 & 75.0 & 3 & 25.0 & 12 & 12.0 \\
\hline \multicolumn{1}{|c|}{ Total } & $\mathbf{1 1 4}$ & $\mathbf{8 4 . 4}$ & $\mathbf{2 1}$ & $\mathbf{1 5 . 6}$ & $\mathbf{1 3 5}$ & $\mathbf{1 0 0 . 0}$ \\
\hline $\begin{array}{l}\text { Chi-square test value } \\
\text { P-value \& Significance }\end{array}$ & \multicolumn{7}{|c|}{$\boldsymbol{\chi}_{\text {yates }}^{\mathbf{2}} \mathbf{1 0 . 4 6 ,}$ P<0.001, } \\
\hline
\end{tabular}

$\mathrm{NS}=$ not significant, $\mathrm{S}=$ significant, $\mathrm{HS}=$ highly significant, VHS=very highly significant

Study observed that, there were $20(95.2 \%)$ of thyroid dysfunction cases have negative TPO among thyroid dysfunction. Only one case
1(4.8\%) had positive TPO among thyroid dysfunction in the study. In the study hospital TPO rate was $4.8 \%$ (Table 6)

Table No.6: TPO wise distribution of thyroid dysfunction cases

\begin{tabular}{|l|c|c|}
\hline TPO & Thyroid dysfunction & Percentage \\
\hline Positive & 1 & 4.8 \\
\hline Negative & 20 & 95.2 \\
\hline Total & 21 & 100.0 \\
\hline
\end{tabular}

Study reveals that, there were no statistical significance difference of mean FT3 and FT4 values among normal and thyroid dysfunction cases $(\mathrm{P}>0.05)$.

Study reveals that, there was statistically very highly significance difference of mean TSH values among normal and thyroid dysfunction cases $(\mathrm{P}<0.001)$.

The mean TSH values of thyroid dysfunction were significantly higher as compare with mean TSH normal values (Table 7)

Table No.7: Comparison of mean TSH, FT3 and FT4 with normal and thyroid dysfunction cases

\begin{tabular}{|l|c|c|c|}
\hline \multirow{2}{*}{ Thyroid profiles } & Normal cases & Thyroid dysfunction cases & $\begin{array}{c}\text { t- test value, } \\
\text { P-value \& Significance }\end{array}$ \\
\cline { 2 - 3 } TSH & Mean \pm SD & Mean \pm SD & $\begin{array}{c}\mathrm{t}=17.48 \\
\mathrm{P}=0.00, \mathrm{VHS}\end{array}$ \\
\hline FT3 & $1.96 \pm 0.89$ & $9.08 \pm 2.31$ & $\mathrm{t}=0.769$ \\
& & & $\mathrm{P}=0.443, \mathrm{NS}$ \\
\hline & $2.73 \pm 0.61$ & $2.78 \pm 0.73$ & $\mathrm{t}=0.802$ \\
FT4 & $12.68 \pm 0.90$ & $12.72 \pm 0.87$ & $\mathrm{P}=0.424, \mathrm{NS}$ \\
\hline
\end{tabular}

Study reveals that, there were no statistical significance difference of Para, Living and
Abortions among normal and thyroid dysfunction cases $(\mathrm{P}>0.05)$. 
Table No.8: Comparison of Para, Living and Abortion cases with normal and thyroid dysfunction cases

\begin{tabular}{|c|c|c|c|c|c|c|}
\hline \multirow[t]{2}{*}{ Variables } & \multicolumn{2}{|c|}{$\begin{array}{l}\text { Normal cases } \\
(\mathbf{N}=114)\end{array}$} & \multicolumn{2}{|c|}{$\begin{array}{l}\text { Thyroid dysfunction cases } \\
\text { (N=21) }\end{array}$} & \multirow[t]{2}{*}{ Total } & \multirow{2}{*}{$\begin{array}{c}\text { Chi-square test, } \\
\text { P-value \& } \\
\text { Significance }\end{array}$} \\
\hline & No. & $\%$ & No. & $\%$ & & \\
\hline Parity & 84 & 73.7 & 12 & 57.2 & 96 & $\begin{array}{l}\chi_{\text {yates }}^{2}=2.36 \\
P>0.05, \quad N S\end{array}$ \\
\hline Living & 77 & 67.5 & 11 & 52.4 & 88 & $\begin{array}{l}\chi_{\text {yates }}^{2}=1.79, \\
P>0.05, \quad \text { NS }\end{array}$ \\
\hline Abortion & 23 & 20.2 & 4 & 19.1 & 27 & $\begin{array}{c}\chi_{\text {yates }}^{2}=0.021 \\
P>0.05, \quad N S\end{array}$ \\
\hline
\end{tabular}

\section{Discussion}

Pregnancy can be viewed as a state, in which a combination of events occurs to modify the thyroid economy ${ }^{(1)}$. There occurs the changes in thyroid hormone levels, TSH levels and even in thyroid binding globulin levels during normal pregnancy.

The thyroid dysfunction can be overlooked in pregnancy because of non specific symptoms and hyper metabolic state. Maternal thyroid dysfunction is associated with complications during pregnancy and can affect both the maternal and fetal outcome ${ }^{(2)}$. Therefore it is important to identify the thyroid disorders, early in pregnancy, so that appropriate measures can be initiated.

Table 1 shows the age distribution of the subjects; majority of the subjects were in the age group of 21-25 years $(56.3 \%)$.

Table 2 shows the obstetric parity wise distribution of cases .so among the study, it was observered that $54(40 \%)$ were primigravida and $81 \%(60 \%)$ were multigravida. which were divided based on number of gravidity.

Table 3 shows the distribution of cases based on period of gestation .From the above it was observed that $68(50.4 \%)$ were belong to in gestation age group of 9-11 weeks. This is similar to study conducted by Nambiar $\mathrm{V}^{1}$ et al which showed that mean gestational age at presentation was $10.03 \pm 1.87$ wks.

Table 4 shows age wise comparision of normal and thyroid dysfunction cases. Study observed that, there were 21 (15.5\%) of thyroid dysfunction cases in the study. The proportion of thyroid dysfunction with normal cases were 5.4:1 and the hospital incidence rate of thyroid dysfunction in first trimester pregnant women was $15.5 \%$ Study reveals that, there was no statistical significance difference of normal and thyroid dysfunction cases in relation with age $(\mathrm{P}>0.05)$.

Table 5 shows comparision of period of gestation with normal and thyroid dysfunction the Study reveals that, there was statistically very highly significance association normal and thyroid dysfunction cases in relation with period of gestation $(\mathrm{P}<0.001)$.

Higher the period of gestation age have significantly more number of thyroid dysfunction cases as compare to lower gestation age in relation with normal cases.

Table 6 shows TPO wise distribution of thyroid dysfunction, Study observed that, there were 20 (95.2\%) of thyroid dysfunction cases have negative TPO among thyroid dysfunction. Only one case $1(4.8 \%)$ had positive TPO among thyroid dysfunction in the study. In the study hospital TPO rate was $4.8 \%$.

Similar study done by Dinesh K. Dhanwan, Sudha Prasad et $\mathrm{al}^{4}$, screened 1000 pregnant women in first trimester. If TSH was deranged, then free T4 and T3 and thyroid peroxidase antibody were done. Their result showed that prevalence of thyroid dysfunction was high in this study, with subclinical hypothyroidism $13.5 \%$, overt hypothyroidism $0.7 \%$, thyrotoxicoses $0.3 \%$ and TPO Ab was positive in $6.82 \%$ of total, $18.5 \%$ of subclinical and $71 \%$ overt hypothyroid patients. 
Table 7 showsComparison of mean TSH, FT3 and FT4 with normal and thyroid dysfunction.Study reveals that, there was statistically very highly significance difference of mean TSH values among normal and thyroid dysfunction cases $(\mathrm{P}<0.001)$. The mean TSH values of thyroid dysfunction were significantly higher as compare with mean TSH normal values. Study reveals that, there were no statistical significance difference of mean FT3 and FT4 values among normal and thyroid dysfunction cases ( $\mathrm{P}$ value were $>0.05$ )

Table 8 shows Comparison of Para, Living and Abortion cases with normal and thyroid dysfunction cases. Study reveals that, there were no statistical significance difference of Para, Living and Abortions among normal and thyroid dysfunction cases $(\mathrm{P}>0.05)$.

The increase in thyroid hormone levels can be attributed to several mechanisms.

During pregnancy, there is an increased concentration of estrogen which influences the increase in the synthesis of hepatic TBGs. It also prolongs the half life of thyroid binding globulins from 15 mins to 3 days because of estrogen induced sialylation. Hence there is decreased hepatic clearance resulting in increase in total T3 and total T4 levels. During pregnancy TBG levels begin to increase after 6-8 weeks of gestation ${ }^{(4)}$ and reaches a plateau around mid gestation and remains high of about 2-3 times of preconception levels until term. Hence the levels of total T4 increase sharply between 6-12 wks of gestation, and progress more slowly thereafter and stabilize around mid gestation. More over the changes in albumin and free fatty acid concentration which facilitates the binding of T4 and T3 to carrier proteins and lowers the concentration of free thyroid hormones levels .This leads to further stimulation of T4 and T3 synthesis. ${ }^{(5,6)}$

The placenta secretes hCG, a glycoprotein hormone, sharing common $\alpha$ subunit with TSH but having unique $\beta$ sub unit, which confers specificity. hCG or a molecular variant, acts as a TSH agonist, having thyrotrophic activity leads to elevated levels of thyroid hormones in first trimester which contribute to the cause of gestational transient hyperthyroxinaemia, seen in about $0.3 \%$ of pregnancies. This is commonly seen in hyperemesis gravidarum, multiple pregnancy and molar pregnancy. ${ }^{8} \mathrm{~T} 4$ is a precursor of T3, which is major active form of thyroid hormone, T4 gets deiodinated to T3 and hence there is increased turnover of T4. This leads to relative hypothyroxemia and an increase in the production of T4 due to increased demand. About $80 \%$ of T3 produced in the body is derived extrathyroidally from T4 deiodination. T4 level is equilibrated in circulation on a manufacture and expenditure basis. Levels of thyroid hormones are determined not only by synthesis /secretion but also by their metabolism. The variations in T3 and T4 levels seems to be need based. ${ }^{15}$

The enzyme type III deiodinase, produced by placenta, converts T4 to rT3 and T3 to diiodotyrosine and it has extremely high activity during fetal life. During fetal life as there is an increased demand for $\mathrm{T} 4$ and $\mathrm{T} 3$ hormones by the fetus, and as it mainly depends on maternal thyroid hormones in early pregnancy until 1214 weeks, it causes an increased production of these hormones which ultimately leads to an increase in circulating concentrations of the same hormones. 8,9

In this study out of 135 pregnant women, the $79(58.51 \%)$ subject had TSH values of $<2.5 \mu \mathrm{IU} / \mathrm{ml}, 34(25.18 \%)$ subjects had TSH values between $2.5-4 \mu \mathrm{IU} / \mathrm{ml}$ and $22(16.29 \%$ ) subjects had TSH values $>4 \mu \mathrm{IU} / \mathrm{ml}$. This variation in TSH values can be explained by following mechanism. Thyroid economy differs between the healthy pregnant women and healthy non pregnant women. Compared with preconceptional levels, TSH concentration is lower throughout the pregnancy. TSH is lowest in the first trimester of pregnancy. $^{2}$

The decrease in TSH level could be attributed to the thyrotrophic action of hCG, which is a thyroid regulator in normal pregnancy, because of hormone specific $\beta$ subunits and extracellular 
receptor binding domains of hCG and TSH share multiple similarities. ${ }^{16}$

In normal pregnancy, the placenta produces hCG in first week of conception and levels peak at week 10 , before decreasing and reaching a plateau by week 20 .

Between 8 and 14 wks of gestation, the changes in hCG and TSH are mirror images of each other, with a significant negative correlation between the two. ${ }^{2}$

The structural homology between hCG and TSH, where they contain a common $\alpha$ subunit and the hormone specific beta subunits share $85 \%$ sequence homology in first 114 amino acid and 12 cysteine residues at highly conserved position, hence their tertiary structures are very similar. ${ }^{17}$

Therefore during first trimester of pregnancy the elevated hCG levels leads to transient increase in thyroid hormone levels and in turn causes partial suppression of TSH secretion,14,12 but not high enough to induce overt hyperthyroidism.37

But according to ATA guidelines, the upper limit of TSH for first trimester of pregnancy is considered as $2.5 \mu \mathrm{IU} / \mathrm{ml}$. Applying the same guidelines to our study population revealed the proportion of euthyroid subjects as $81.5 \%, 16.3 \%$ as hypothyroid (subjects had TSH values > $2.5 \mu \mathrm{IU} / \mathrm{ml}$ ), and $2.5 \%$ (subjects had TSH values $<0.04 \mu \mathrm{IU} / \mathrm{ml}$ ), as hyperthyroid. There has been a wide geographic variation in prevalence of hypothyroidism during pregnancy. It varies from $2.5 \%$ in west to $11 \%$ in India, It seems that prevalence of hypothyroidism is more in Asian countries as compared to west ${ }^{38}$.

The present study is in agreement with the study conducted by Dinesh $\mathrm{DK}^{10}$ et al, where in the incidence of hypothyroidism was found to be $14.3 \%$ during first trimester of pregnancy.

The observations of present study is similar to the study conducted by Nambier $\mathrm{V}^{1}$ et al, who reported the prevalence of hypothyroidism and thyroid autoimmunity as $4.8 \%$ and $12.8 \%$ respectively.
This study is also in favour of study conducted by sahasrabuddhe $\mathrm{A}^{11}$ et al who reported the prevalence of hypothyroidism as $>10 \%$.

A study done by Mukhopadhyay $\mathrm{A}^{12}$ et al reported the incidence of hypothyroidism in pregnancy about $3.69 \%$ unlike the observations found in the present study.

A study by Goel $\mathrm{P}^{13}$ et al reported the prevalence of hypothyroidism of about $6.3 \%$ which is in favour of the findings of the present study.

A study done by Shah $\mathrm{MJ}^{18}$ et al reported the prevalence of hypothyroid in $4.4 \%$ and overt hyperthyroidism in $0.6 \%$ in their study subjects which is quite less compared to the observations of the present study.

The subjects in hyperthyroid state could be due to gestational transient thyrotoxicosis (GTT) which occurs in $1-3 \%$ of pregnancies, due to elevated hCG levels or due to overt hyperthyroidism which occurs in 0.4-0.7\% of pregnancies.

This is in support of the fact that there is a high prevalence of gestational thyrotoxicosis in Asian women during 8-11weeks of gestation than during 1214 weeks. $^{14}$

\section{Conclusion}

Limitations of this study, were fT3 \& fT4\&TSH levels were estimated, hence the categorization of thyroid dysfunction (subclinical / overt hypothyroidism or hyperthyroidism) could not be confirmed.

Larger sample size is required to get a better idea about the incidence /prevalence of thyroid dysfunction in this population, unlike this study which has a sample size of 135 .

As the ATA guidelines have been framed for the western population, the estimation of thyroid abnormalities based on these guidelines in this present study might have been over estimated or underestimated.

A case series study was conducted in apparently normal first trimeseter pregnant women to determine the thyroid status and also to assess the abnormalities associated with it. 
The following conclusion can be drawn from this study.

The TSH significantly increased in the age group of 21-25 years of patient as compared to other age group considered in this study.

Applying ATA guidelines for TSH values in the present study showed that $84.44 \%$ were eythyroid, $15.5 \%$ were hypothyroid among them only was TPO ab positive state.

So to conclude, The thyroid dysfunction determined based on TSH values (as per ATA guidelines) is quite high. This indicates proportion of the thyroid dysfunction present in the local population.

Further studies are required in this regard in a larger population so that gestational age specific reference intervals can also be established for local population of particular geographic area to avoid misinterpretation of thyroid function tests during first trimester of pregnancy.

\section{References}

1. Nambiar V, Varsha S, Jagthap, Sarathi V, Anurag R et al. Prevelence and impact of thyroid disorders on maternal outcome in Asian-Indian pregnant women. J Thyroid Research. 2011;2011:429097.

2. Cynthia F, Yazbeck, Shannon D, Sullivan. Med clin N Am 96(2012) 235-256.

3. Gilbert MR, Hadlow CN, Walsh PJ, Fletcher JS, Brown JS et al. Assessment of thyroid function during pregnancy: firsttrimester (weeks 9-13) reference intervals derived from Australian women. MJA 2008;189(5):250-253

4. Stagnaro-GA, Abalovich, Alexander E, Fereidoun A, Mestman J, Negro R, Nixon A et al. Guide lines of American thyroid association for the diagnosis.

5. Cynthia F, Yazbeck, Shannon D, Sullivan. med clin N Am 96(2012) 235-256.

6. Lazarus J. Thyroid regulation and dysfunction in pregnant patient, updated :October 1,2011
7. Lazarus HJ. Thyroid function in pregnancy .British medical bulletin 2011; 97: 137148

8. Zhargami N, Naubar MR, Khosrowbeygi A. Thyroid hormones status during pregnancy in normal Iranian women. Indian J Clin Biochem 2005;20(2):182-85

9. Pasupathi. P, Chandrashekar V, Senthilkumar. U. Thyroid hormone changes in pregnant and non pregnant women.2009 .Thyrroid Science 4(3):CLS1-5

10. Dhanwal DK, Sudha P, Agarwal AK, Vivek D, Banerjee AK . High prevalence of subclinical hypothyroidism during first trimester pregnancy in north India. Indian $\mathrm{J}$ of endocrmetab2013;17:281-284.

11. Sahasrabuddhe A, Pitale S. Screening of thyroid dysfunction during pregnancy. Thyroid research and practice.2012; 9:1518.

12. Mukhopadhyay A, pati S, Mukherjee S, Das N, Mukhopadhyay P, Saumandal B. Autoimmune thyroid disease and pregnancy outcome-a prospective observational study. Thyroid research and practice.

13. Goel P, Kaur J, Suha PK, Tondon R, Devi L. Prevelence, a associated risk factor and effects of hypothyroidism in pregnancy; A study from north India.

14. Yeo CP, Khoo DH, Eng PH, Tan HK, Yo SL, Jacob E. Prevalence of gestational thyrotoxicosis in Asian women evaluated in 8th to 14th week pregnancy. Correlation with total and free beta human chorionic gonadotropin. Clin. Endocrinol 2001;55:391-398.

15. Jabbar AAK, Qassium MH, Shnayeh AJK. Clinical evaluation of T3, T4 and TSH thyroid function during first, second and third trimester of pregnancy in Iraqi pregnant women. Journal of Medicine and Medical Science 2012;3(3):195 
16. Mujawar AS, Patil VW, Daver GR. Human chorionic gonadotrophin and thyroid hormone status during normotensive pregnancy. $\mathrm{J}$ of pharmaceutical and bio med sci. 2010;2(01)

17. Yoshimura M, Hershman J M. Thyrotropic action of human chorionic gonadotropin. 1955;5:425-434.

18. Shah MJ, Meghana N, Mehta, Viradia BH. Screening for thyroid dysfunction during pregnancy; Thyroid research \& practice. May-Aug2013; vol 10, issue 2. 